\title{
CMR validation of fractional changes in annulo- apical angles and TAPSE for rapid assessment of right ventricular systolic function
}

\author{
Simon A Zakerii ${ }^{3, *^{*}}$, Alexander Borg ${ }^{2}$, Matthias Schmitt ${ }^{2,1}$ \\ From 15th Annual SCMR Scientific Sessions \\ Orlando, FL, USA. 2-5 February 2012
}

\section{Background}

Volumetric assessment of the right ventricle (RV) by Cardiac Magnetic Resonance (CMR), albeit time-consuming, provides accurate and reproducible measurement of RV ejection fraction (RVEF). Tricuspid annulus peak systolic excursion (TAPSE) is a predominantly Echo-validated rapidly-derived surrogate of RV function. Correlations between RVEF and systolic changes in annulo-apical angles (AAAs) have not previously been evaluated.

\section{Objective}

To assess the use of changes in AAAs and TAPSE as rapidly-derived surrogate markers of RV systolic function using CMR.

\section{Methods}

We measured RV volumes from short-axis bSSFP stacks in patients undergoing clinically indicated CMR scans. RVEF was calculated from volumes derived by semiautomated endocardial contouring (QMass ${ }^{\circledR}$ MR 7.2). AAAs ( $\alpha, \beta, \theta$ angles -see figure 1$)$, subtended by a triangle connecting the medial and lateral extent of the tricuspid valve annulus and RV apex, and fractional changes in AAAs ( $\triangle \mathrm{AAA} / \mathrm{EDAAAx} 100$, whereby $\triangle \mathrm{AAA}=$ EDAAA-ESAAA) were measured from end-diastolic (ED) and end-systolic (ES) 4chamber SSFP cine still frames. TAPSE was measured as the change in length of a line connecting the lateral tricuspid valve annulus with the RV apex from ED to ES. Parameters were compared with RVEF using Spearman rank

${ }^{3}$ Manchester Medical School, Manchester, UK

Full list of author information is available at the end of the article

correlations; ROC curves constructed to assess accuracy of the parameters in predicting an $\mathrm{RVEF}<50 \%$.

\section{Results}

Forty subjects were included: 10 normals, 10 mildlyimpaired, 10 moderately-impaired, and 10 with severelyimpaired RV systolic function. Median (25th-75th percentile) RVEF for each subgroup was 53.5\% (51.4\%$55.7 \%), 41.5 \%$ (38.1\%-47.2\%), 30.0\% (21.7\%-33.5\%), and $15.8 \%$ (9.6\%-21.2\%), respectively. Correlations with RVEF: TAPSE $(0.74 \mathrm{p}<0.001)$, fractional changes of $\alpha$ angle $(0.64, \mathrm{p}<0.001), \beta$ angle $(-0.39, \mathrm{p}<0.05)$, and $\theta$ angle, which had the highest correlation $(-0.77$, $\mathrm{p}<0.001)$. Smaller increases or a decrease in magnitude of the $\theta$ angle from ED to ES are associated with lower RVEFs, whereby a fractional $\theta$ angle change of $\geq-25.5 \%$ predicts $\mathrm{RVEF}<50 \%$ [ $97 \%$ sensitivity, $91 \%$ specificity, AUC $=0.98]$. The cut-off for TAPSE is $\leq 1.87 \mathrm{~cm}[100 \%$ sensitivity, $82 \%$ specificity, AUC $=0.98]$. Intra- and interobserver reproducibility is excellent as shown by intraclass correlation coefficients for TAPSE (0.98 and 0.92, respectively) and fractional $\theta$ angle change (0.96 and 0.80 , respectively).

\section{Conclusions}

Both fractional $\theta$ angle change and TAPSE strongly correlate with RVEF, and are accurate predictors of RVEF $<50 \%$. These measurements provide an excellent alternative to the more time-consuming derivation of RVEF obtained volumetrically by endocardial chamber tracing.

\section{Funding}

No funding.

(c) 2012 Zakeri et al; licensee BioMed Central Ltd. This is an open access article distributed under the terms of the Creative Commons 


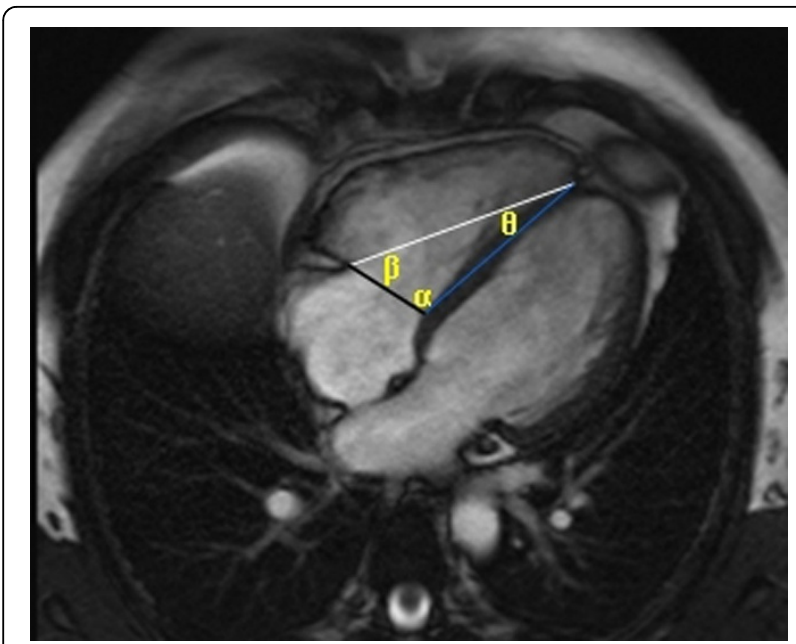

Figure 1 AAAs in ED on a 4chamber view.

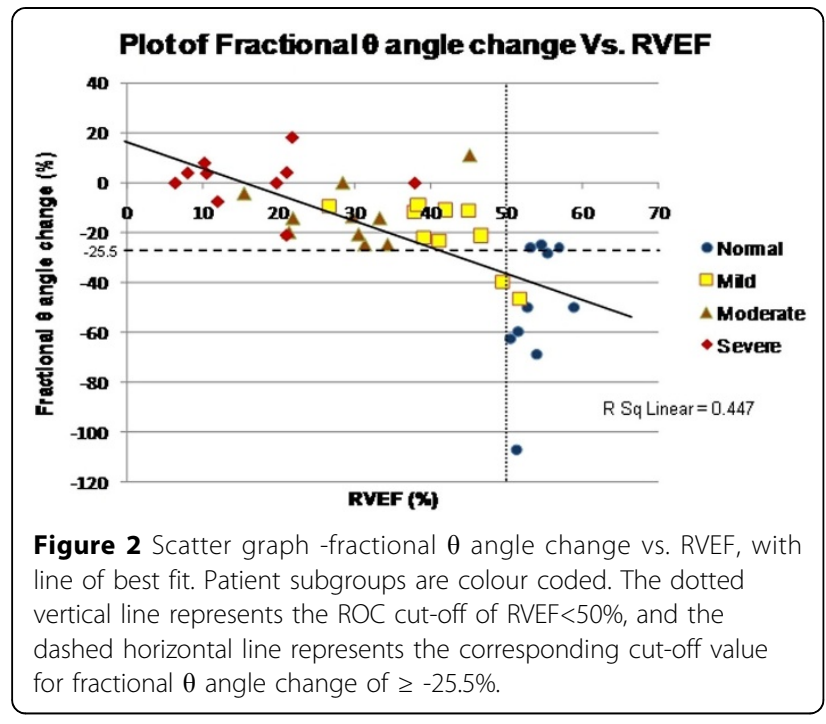

\section{Author details}

${ }^{1}$ University of Manchester, Manchester, UK. ${ }^{2}$ Cardiology, Cardiovascular Division, University Hospital of South Manchester, Manchester, UK.

${ }^{3}$ Manchester Medical School, Manchester, UK.

Published: 1 February 2012

doi:10.1186/1532-429X-14-S1-P284

Cite this article as: Zakeri et al: CMR validation of fractional changes in annulo-apical angles and TAPSE for rapid assessment of right

ventricular systolic function. Journal of Cardiovascular Magnetic Resonance 2012 14(Suppl 1):P284

\section{Submit your next manuscript to BioMed Central} and take full advantage of:

- Convenient online submission

- Thorough peer review

- No space constraints or color figure charges

- Immediate publication on acceptance

- Inclusion in PubMed, CAS, Scopus and Google Scholar

- Research which is freely available for redistribution 